\title{
Tuberculous pseudoaneurysm of the ascending aorta
}

\author{
Sowmya Gopalan, Srinivasan Ramadurai, Aiswarya Manmadhan Nair, Preetam Arthur
}

Department of General Medicine, Sri Ramachandra University, Chennai, Tamil Nadu, India

\section{Correspondence to} Professor Sowmya Gopalan, sowmya_js@yahoo.com

Accepted 19 September 2015

\section{SUMMARY}

Increase in the incidence of drug resistance and association with HIV has led to a resurgence of tuberculosis. However, tubercular arteritis continues to remain a rare entity with a prelidection for the thoracic aorta. We report a tubercular ascending aortic pseudoaneurysm in a patient already on treatment for disseminated tuberculosis who underwent successful surgical repair and also review literature pertaining to this entity.

\section{BACKGROUND}

Aortic mycotic aneurysms due to tuberculosis are very rare and life-threatening. The clinical features are highly variable, ranging from asymptomatic aneurysm to pressure symptoms like chest pain, dysphagia, back pain, to the presence of pulsatile mass to frank rupture, bleeding and shock. ${ }^{1}$

This condition is seen usually in association with disseminated tuberculosis. Early diagnosis is vital as outcomes are dependent on early surgery. The rising incidence of multidrug resistant and extremely drug resistant tuberculosis may cause an increase in diagnosis of tuberculosis in unusual sites such as aorta. We describe a case of a large tuberculous pseudoaneurysm in our patient on treatment for disseminated tuberculosis.

\section{CASE PRESENTATION}

A 31-year-old woman presented with a 1 month history of fever, loss of appetite and weight and altered sensorium for 5 days. On examination, she was febrile, her Glasgow coma score was 13/15. Chest examination was unremarkable and nervous system examination revealed no focal deficits. In view of prolonged fever, tuberculosis was considered as a possibility. Central nervous system imaging showed tuberculoma brain and CT thorax showed bilateral extensive military mottling suggestive of miliary tuberculosis (figure 1). Aorta appeared normal. There was no underlying immunocompromised state. She was diagnosed to have disseminated tuberculosis and started on antituberculous therapy (ATT) with isoniazid $(\mathrm{H})$, rifampicin (R), ethambutol (E) and pyrazinamide (Z) along with steroids. She developed drug-induced hepatitis which warranted cessation of ATT. She was put on levofloxacin, streptomycin and ethambutol. On normalisation of liver functions, ATT was reinitiated and uptitrated and she was discharged on HRZE.

She presented after 2 months with symptoms of right-sided chest pain and palpitations for 5 days and breathlessness for 3 days. Clinical examination revealed no abnormality.

\section{INVESTIGATIONS}

Chest X-ray posteroanterior view showed new onset mediastinal widening (figure 2). Repeat CT thorax showed large pseudo aneurysm of size $87 \times 68 \times 95 \mathrm{~mm}$ arising from ascending aorta (figures 3 and 4). No thrombus or calcification was seen. Transthoracic echo revealed mild pulmonary hypertension (pulmonary artery pressure of $50 \mathrm{~mm} \mathrm{Hg}$ ). Blood culture was sterile.

\section{TREATMENT}

Patient was taken up for surgery. After securing the cardiopulmonary bypass via femoral arterial access, as the aorta was clamped, the ascending aorta pseudo aneurysm ruptured. Repair with ascending aorta patch collage coated polyester pericardiectomy was performed. Postoperative period was uneventful and X-ray (figure 5) was normal and antituberculous chemotherapy was continued for a total of 9 months. Culture of the tissue was sterile. Histopathological examination revealed ill-defined granulomas with epitheloid cells which was consistent with tuberculosis.

\section{OUTCOME AND FOLLOW-UP}

Patient was followed up for 1 year and is doing well.

\section{DISCUSSION}

Sir William Osler first coined the term mycotic aneurysm to describe multiple beadlike aneurysms in the vessel wall due to infectious origin. ${ }^{2}$ Tuberculosis is a rare cause of infected aneurysms. Long $e t a l^{1}$ in their review of the tuberculous aneurysm of the entire aorta, described three

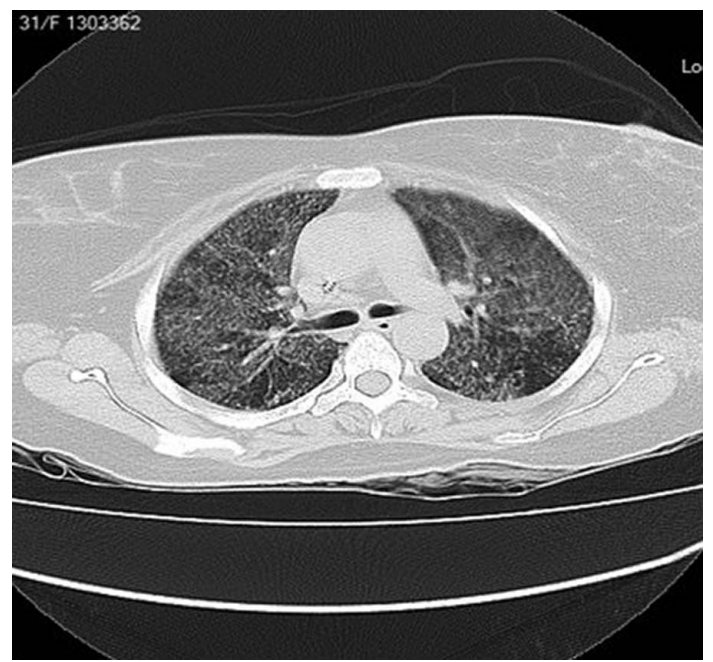

Figure $1 \mathrm{CT}$ of the thorax showing military mottling. 


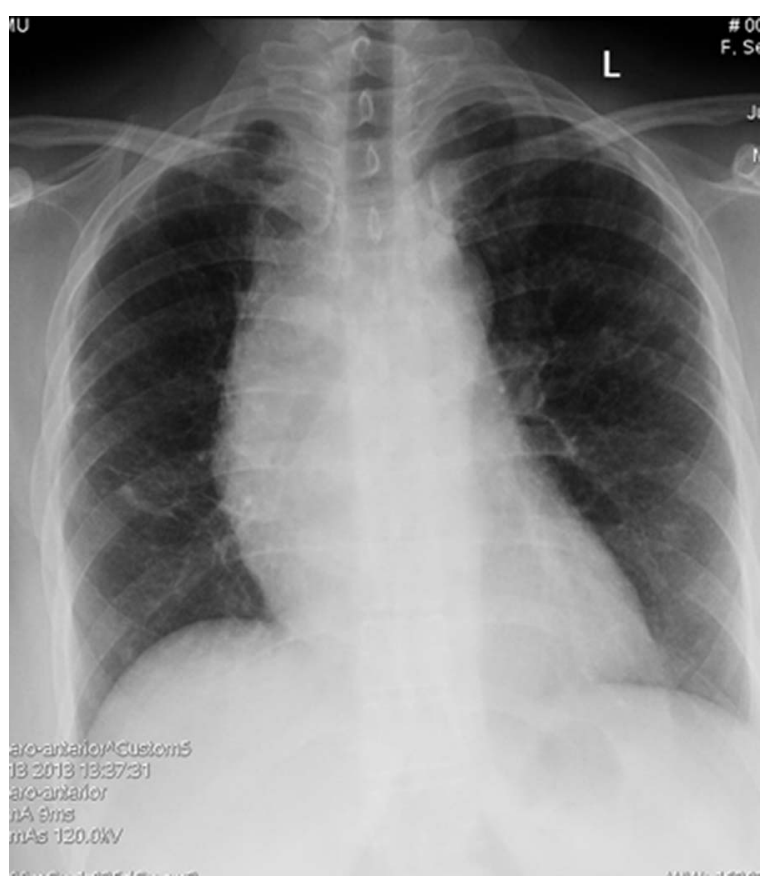

Figure 2 Chest X-ray showing mediastinal widening.

possible ways the tubercle bacilli reached the aortic wall and the commonest method was due to local infiltration such as erosion of periaortic lymph nodes into the aortic wall. In our patient too, extension from the contiguous focus was the most likely mechanism.

The most common location of tuberculous aneurysms has been the thoracic aorta. This has been attributed to the anatomical proximity of the thoracic aorta to the lungs and mediastinum where the disease most commonly occurs. ${ }^{3}$ Five types of tuberculous arterial disease have been described. Haythorn described tuberculous aneurysm, intimal polyp, panarteritis and military tuberculosis with intimal involvement. ${ }^{4}$ A fifth type, aortoarteritis, due to hypersensitivity to tuberculous antigens,

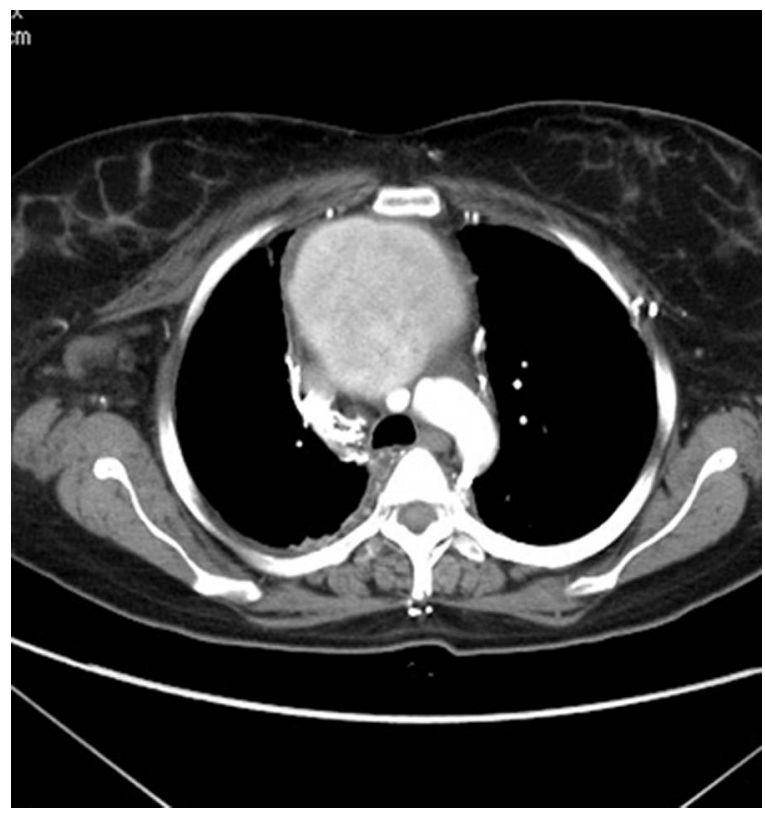

Figure $3 \mathrm{CT}$ of the thorax with ascending aortic aneurysm.

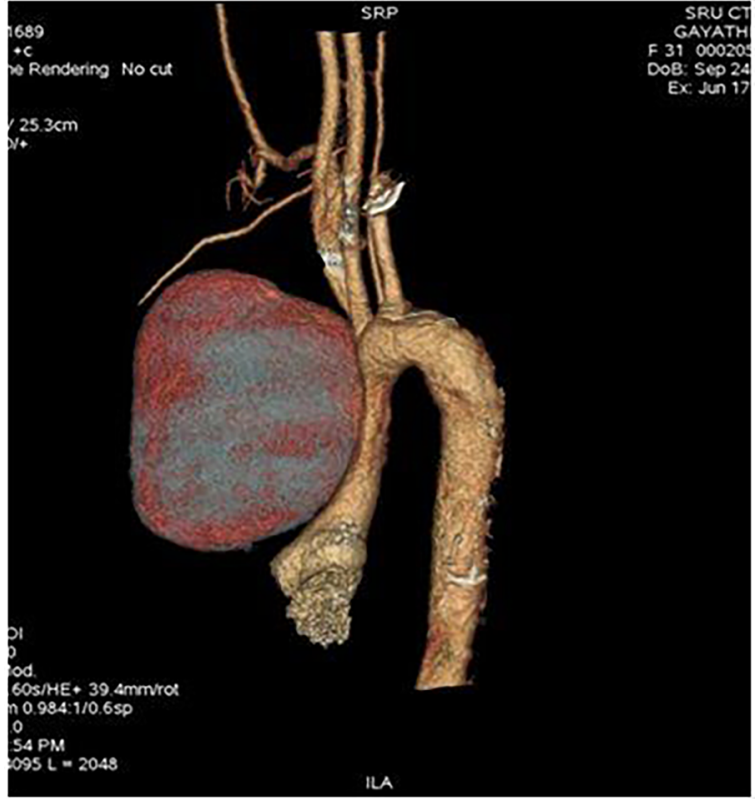

Figure 4 Reconstructed image of the ascending aortic pseudoaneurysm.

causing aortic wall stenosis was reported from India. ${ }^{5}$ Most are pseudoaneurysms though occasional true and dissecting aneurysms have been reported.

Most of the early reports of tuberculous pseudoaneurysms were from autopsy specimens. In 1955, Rob and Eastcott ${ }^{6}$ reported the first successfully surgically treated patient with tuberculous aneurysm. Since then, less than 100 cases have been reported. Many patients were diagnosed to have tuberculosis only when the pseudoaneurysms were evaluated though there was pre-existing tuberculosis in reports from Asia including ours. ${ }^{7}$ Sudden deterioration in general condition in a patient on treatment is a vital clue. ${ }^{7}$ The percentage of patients with pseudoaneurysms who had disseminated tuberculosis was also high. ${ }^{1}$

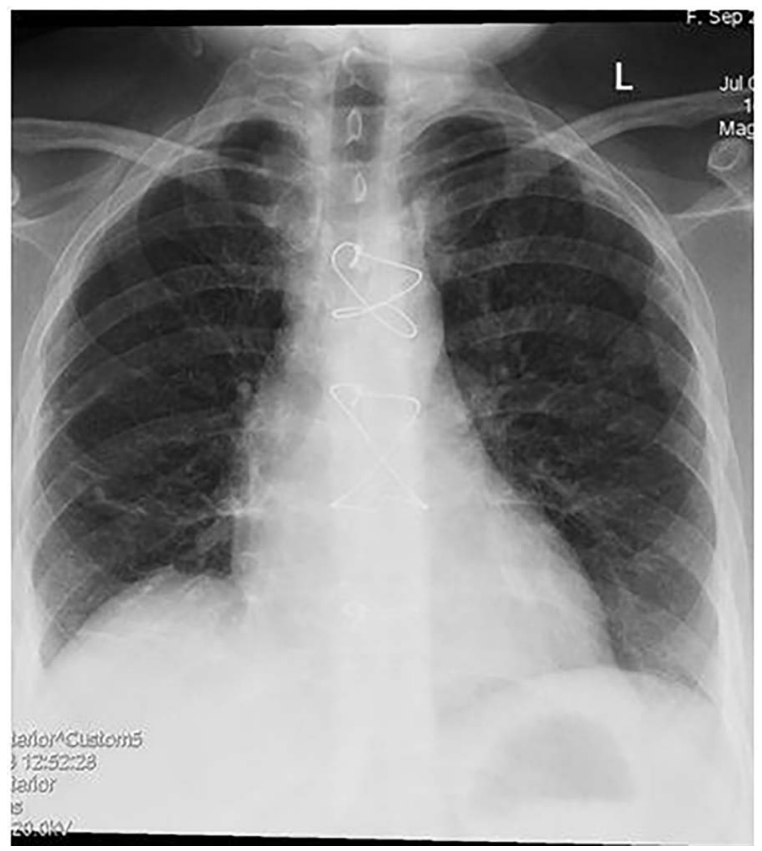

Figure 5 Postoperative chest X-ray showing normal mediastinum.

Gopalan S, et al. BMJ Case Rep 2015. doi:10.1136/bcr-2015-211910 
Outcomes have been better when it has been diagnosed early and with a combination of early surgery and aggressive

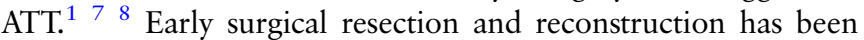
the treatment of choice. In recent years, endovascular therapy with stent placement has also been reported to give good results in thoracic and abdominal aneurysms. ${ }^{8}$ The role of ATT cannot be over emphasised. Delay in initiation of drug therapy has resulted in adverse outcomes.

\section{Learning points}

- Tuberculous aortitis is seen mostly in patients with disseminated tuberculosis.

- Thoracic aorta is the most common site of tuberculous pseudoaneurysms.

- Sudden deterioration in general condition with new onset of chest symptoms warrants evaluation for aneurysm.

- Early surgery or endovascular therapy combined with antituberculous therapy gives good outcomes.
Competing interests None declared.

Patient consent Obtained.

Provenance and peer review Not commissioned; externally peer reviewed.

\section{REFERENCES}

1 Long R, Guzman R, Greenberg $H$, et al. Tuberculous mycotic aneurysm of the aorta—a review of published medical and surgical experience. Chest 1999;115: 522-31.

2 Osler W. The Gulstonian lectures on malignant endocarditis. BMJ 1885;1:467-70.

3 Silbergleit A, Arbulu A, Defever BA, et al. Tuberculous aortitis: surgical resection of ruptured abdominal false aneurysm. JAMA 1965;193:333-5.

4 Haythorn SR. Tuberculosis of the large arteries. JAMA 1913;60:1413-16.

5 Gajraj A, Victor S. Tuberculous aorta arteritis. Clin Radiol 1981;32:461-6.

6 Rob CG, Eastcott HHG. Aortic aneurysm due to tuberculous lymphadenitis. Br Med J 1955;1:378-9.

7 Choudhary SK, Bhan A, Talwar S, et al. Tubercular pseudoaneurysms of aorta. Ann Thorac Surg 2001;72:1239-44.

8 Dogen S, Memis A, Kale A, et al. Endovascular stent graft placement in the treatment of ruptured tuberculous pseudoaneurysm of the descending thoracic aorta: case report and review of the literature. Cardiovasc Intervent Radiol 2009:32:572-6.

Copyright 2015 BMJ Publishing Group. All rights reserved. For permission to reuse any of this content visit http://group.bmj.com/group/rights-licensing/permissions.

BMJ Case Report Fellows may re-use this article for personal use and teaching without any further permission.

Become a Fellow of BMJ Case Reports today and you can:

- Submit as many cases as you like

- Enjoy fast sympathetic peer review and rapid publication of accepted articles

- Access all the published articles

- Re-use any of the published material for personal use and teaching without further permission

For information on Institutional Fellowships contact consortiasales@bmjgroup.com

Visit casereports.bmj.com for more articles like this and to become a Fellow 